\title{
Psychiatric Adverse Reactions to Anaplastic Lymphoma Kinase Inhibitors in Non-Small-Cell Lung Cancer: Analysis of Spontaneous Reports Submitted to the FDA Adverse Event Reporting System
}

\author{
Monia Sisi ${ }^{1}\left[\right.$ Michele Fusaroli $^{2} \cdot$ Andrea De Giglio $^{1,3} \cdot$ Francesco Facchinetti $^{4} \cdot$ Andrea Ardizzoni $^{1,3}$. \\ Emanuel Raschi ${ }^{2} \cdot$ Francesco Gelsomino $^{1,3}$
}

Accepted: 16 December 2021 / Published online: 13 January 2022

(c) The Author(s) 2022

\begin{abstract}
Background The development of anaplastic lymphoma kinase (ALK) tyrosine kinase inhibitors (TKIs) has improved the survival outcomes of patients with advanced ALK-rearranged non-small-cell lung cancer (NSCLC). The adverse events (AEs) related to ALK inhibitors are fairly well known; notably, about $20 \%$ of patients receiving lorlatinib experienced cognitive effects and behavioral alterations in pivotal trials. Therefore, psychiatric disorders could represent AEs of special interest for all ALK TKIs, deserving careful assessment in the post-marketing setting.

Objective We conducted a real-world pharmacovigilance study on psychiatric AEs with marketed ALK inhibitors in subjects with advanced NSCLC.

Patients and methods We performed an observational, retrospective analysis of spontaneous reports submitted to the Food and Drug Administration Adverse Events Reporting System (FAERS, as of December 2020), selecting psychiatric AEs to ALK TKIs approved in NSCLC (crizotinib, ceritinib, alectinib, brigatinib, lorlatinib). These AEs were independently scrutinized by three oncologists applying predefined exclusion criteria, described in terms of clinical/demographic features and assessed for drug-related causality according to an adaptation of the WHO-UMC system, a standardized probabilistic algorithm.

Results Among 584 reported psychiatric AEs, 95 cases were selected as potentially treatment related, with higher reporting frequency for lorlatinib $(26,2.8 \%)$, followed by brigatinib $(10,1.2 \%)$, alectinib $(18,0.7 \%)$, ceritinib $(12,0.6 \%)$, and crizotinib (29, 0.3\%). Reported psychiatric symptoms were mood disorders (39), psychotic disorders (24), and anxiety, agitation, and irritability (25). In the majority (74\%) of cases, psychiatric AEs were serious and required hospitalization in about $32 \%$ of patients; $15.8 \%$ of retained cases were considered as highly probable and $69.5 \%$ as probable. Drug discontinuation was recorded in $31.6 \%$ of the reported cases, with the highest proportion for lorlatinib (65.4\%).

Conclusion Notwithstanding limitations, our study found a higher proportion of psychiatric AEs with lorlatinib, but also raised the hypothesis of psychiatric reactions as a class effect of ALK TKIs.
\end{abstract}

\section{Introduction}

Anaplastic lymphoma kinase $(A L K)$ gene rearrangements account for $4-6 \%$ of all non-small-cell lung cancers (NSCLCs) [1]. Echinoderm microtubule-associated

Monia Sisi and Michele Fusaroli contributed equally.

Emanuel Raschi and Francesco Gelsomino contributed equally.

Monia Sisi

monia.sisi@studio.unibo.it

Extended author information available on the last page of the article protein-like 4 (EML4) gene represents the most frequent partner involved in rearrangement gene process, resulting in the fusion oncogene EML4-ALK. ALK rearrangements are often associated with specific clinical features, such as never- or light-smoking history, young age (median age $\sim 50$ years), adenocarcinoma histology and central nervous system (CNS) metastatic involvement at diagnosis or during disease evolution [2].

Different methods such as fluorescence in situ hybridization, immunohistochemistry, and next-generation sequencing are the gold-standard assays to test $A L K$ gene fusion and are routinely used in patients with advanced 


\section{Key Points}

Spontaneous reporting systems are needed to detect and better characterize adverse events (AEs) with anaplastic lymphoma kinase (ALK) inhibitors in a timely manner in the real world.

Although rare, psychiatric disorders submitted to FAERS represent AEs of special interest with ALK inhibitors, the majority being serious, with probable causality.

This real-world pharmacovigilance study on marketed ALK inhibitors suggested that psychiatric AEs are adverse reactions to ALK TKIs, and raised the hypothesis of a class effect.

non-squamous NSCLC [3]. NSCLC harboring $A L K$ gene fusions are sensitive to ALK tyrosine kinase inhibitors (TKIs), which demonstrated impressive response rates and significantly improved survival outcomes. The PROFILE 1014 trial was the first phase III study to demonstrate higher activity and efficacy outcomes of crizotinib, a firstgeneration ALK TKI, over standard platinum-pemetrexed chemotherapy as first-line treatment in advanced ALKpositive NSCLC patients [4]. Subsequently, the second(alectinib, brigatinib) and third-generation (lorlatinib) ALK TKIs showed higher CNS activity and better efficacy than crizotinib [5-8]. Currently, these novel-generation ALK TKIs are administered as first-line therapy, allowing long-term disease control (approaching the 3 years for alectinib and brigatinib) $[9,10]$ and a peculiar activity against brain metastases (BM) [5-7, 9-11].

In pivotal studies of first-line ALK TKIs, the most common (of any grade) treatment-related adverse events (AEs) were vision disorders (about $70 \%$ for crizotinib), nausea and diarrhea (respectively up to $69 \%$ and $85 \%$ with ceritinib and $49 \%$ with brigatinib), hypercholesterolemia (up to $70 \%$ with lorlatinib), hypertriglyceridemia (64\% with lorlatinib), peripheral edema (up to $17 \%$ with alectinib and $55 \%$ with lorlatinib), anemia (15\% of cases with ceritinib and $19 \%$ with lorlatinib), increased alanine aminotransferase (up to $58 \%$ with ceritinib) and aspartate aminotransferase (up to $32 \%$ with ceritinib), for which interruption and dose modification could be needed [4-7, 11]. Because ALK TKIs are administered for a long period of time, both efficacy and tolerability are key determinants of treatment choice [12]. Early observations of potential different toxicity profiles can encourage physicians to switch to a different ALK TKI when encountering an AE requiring treatment discontinuation [13].
Notably, $23 \%$ of patients treated with lorlatinib, a brainpenetrant ALK TKI, experienced cognitive effects (such as memory impairment, cognitive disorders, and amnesia), and behavioral alterations were reported in up to $21 \%$ of cases, most frequently as irritability, anxiety, depression, and affection lability [14]. The actual clinical and epidemiological impact of some relatively rare AEs, such as psychiatric disorders, can be better assessed in real-world experience than in registration trials. Therefore, post-marketing studies are needed to describe rare and unexpected toxicities for drugs marketed through accelerated approval [15].

We conducted a real-world pharmacovigilance study on psychiatric AEs with ALK TKIs for NSCLC submitted to the publicly available Food and Drug Administration Adverse Events Reporting System (FAERS).

\section{Methods}

The study was conceived as an observational, retrospective pharmacovigilance analysis of FAERS, a recognized source for timely real-world safety assessment of anticancer drugs [16].

We queried the FAERS public dashboard to select AEs reported for the following ALK TKIs approved in NSCLC: crizotinib, alectinib, ceritinib, brigatinib, and lorlatinib.

Reported psychiatric AEs were analyzed to remove potential duplicates (e.g., records overlapping in key fields such as age, sex, reporter's country, drugs, and symptoms), and the remaining cases were further scrutinized by three physicians independently by applying the following exclusion criteria: (1) clinical features, including neurologic events (delirium, insomnia, dizziness, disorientation, dementia) or CNS disease progression, (2) comorbidities (e.g., fever and infections, which may cause delirium and disorientation), (3) concomitant drugs as a proxy of pre-existing psychiatric diseases/susceptibility (antipsychotic drugs, benzodiazepines, psychostimulant drugs in relation to the type of reported symptoms), and (4) therapeutic indications outside advanced ALK-positive NSCLC (e.g. lymphoma) (Fig. 1). Each case was retained if at least two clinicians were in agreement.

Selected cases were described in terms of demographic features (e.g., age, sex, reporter Country), clinical features (e.g., signs/symptoms, seriousness, discontinuation, brain involvement), and assessed for causality (categorized as highly probable, probable, possible, unlikely) according to an adaptation of the standardized WHO-UMC system, a probabilistic algorithm (Electronic Supplementary Material, ESM). To this purpose, the following clinical features were inspected: (1) time to onset of psychiatric symptoms (calculated as the delay between the beginning of the therapy and the date the event occurred, expressed as days with 
interquartile range (IQR)), (2) dechallenge (clinical improvement after the suspected agent was withdrawn, according to the reporter), and rechallenge (occurrence of a similar reaction after re-administration, usually unintentional), (3) presence of CNS metastases, (4) concomitant drugs known to cause psychiatric AEs (corticosteroids and/or hydroxychloroquine); (5) role assigned by the reporter to the ALK TKI (suspect or concomitant). Highly probable cases were those with plausible time to onset (i.e., the event was recorded after ALK TKI initiation), alternative causes ruled out, and positive dechallenge and/or rechallenge.

\section{Results}

\subsection{Demographic Characteristics}

As of December 2020, 14,323 cases of all AEs suspected to be related to ALK TKIs were reported, and 95 (0.7\%) of them were retained as psychiatric AEs (Fig. 1). For alectinib and lorlatinib psychiatric AEs were collected since 2016; for crizotinib, since 2012, for ceritinib since 2014, and for brigatinib since 2017 .

Psychiatric symptoms most frequently reported were mood disorders (39 patients), psychotic disorders (24 patients), and anxiety, agitation and irritability (25 patients); other reported AEs were sleeping, cognitive and eating disorders, fear and panic attacks, and abnormal behaviors, with six attempted or completed suicide cases.
The highest number of psychiatric reports emerged for crizotinib (29, $0.3 \%$ of relevant reports), followed by lorlatinib (26, 2.8\%), alectinib (18,0.7\%), ceritinib $(12,0.6 \%)$, and brigatinib (10,1.2\%) (Table 1). In general, a female preponderance emerged $(65.6 \%)$, with $51.6 \%$ of the cases submitted by North America. Physicians were the main source of reports (43.9\%), followed by consumers (36.4\%).

The age group most frequently affected by psychiatric AEs was 30-49 years for lorlatinib and alectinib, whereas older patients (50-64 years) were especially represented for crizotinib, brigatinib, and ceritinib.

\subsection{Clinical Features and Outcomes}

In the time-to-onset analysis, the latency of psychiatric AEs from drug initiation was lower for lorlatinib (5 days, median; IQR [3-15] calculated on seven patients) and alectinib (25 days [8-70] calculated on five patients) as compared to crizotinib (115 days [17-258] calculated on ten patients) and ceritinib (just one case, with onset after almost 3 years from the first administration). Time-to-onset data were missing for brigatinib. In a minority of cases, concurrent steroid therapy was reported (11.6\%); brain involvement was noticed for five (5.3\%) patients.

In the majority (73.7\%) of cases, psychiatric AEs were serious and required hospitalization in $30(31.6 \%)$ patients, up to $55.6 \%$ as reported for alectinib; finally, death or lifethreatening events were recorded in ten $(10.5 \%)$ patients. Of note, discontinuation and positive dechallenge were recorded
Fig. 1 Flow chart showing the selection of psychiatric adverse events reported with anaplastic lymphoma kinase (ALK) tyrosine kinase inhibitors (TKIs) in food and drug administration adverse events reporting system (FAERS). * The same report can be excluded for multiple reasons

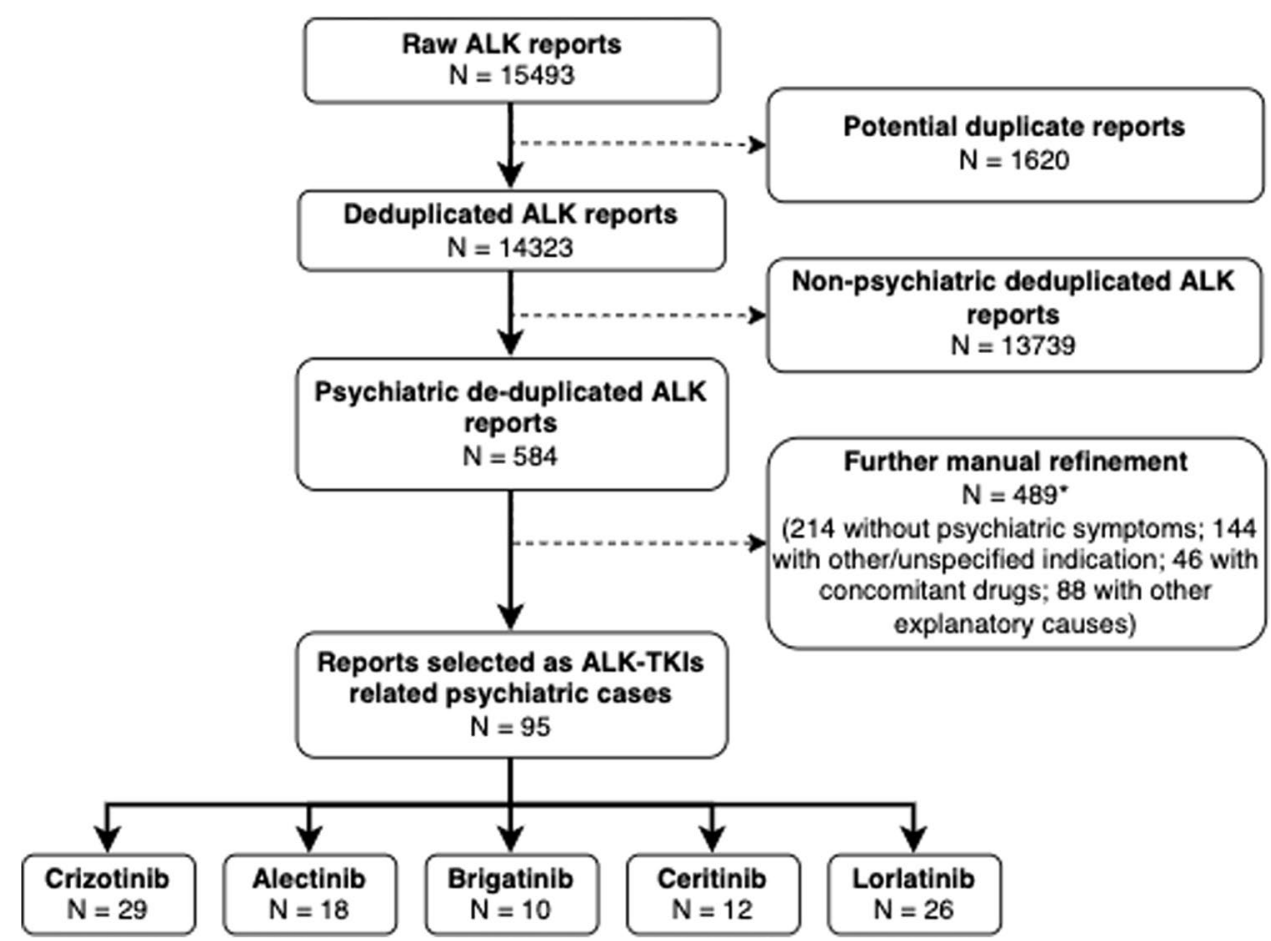




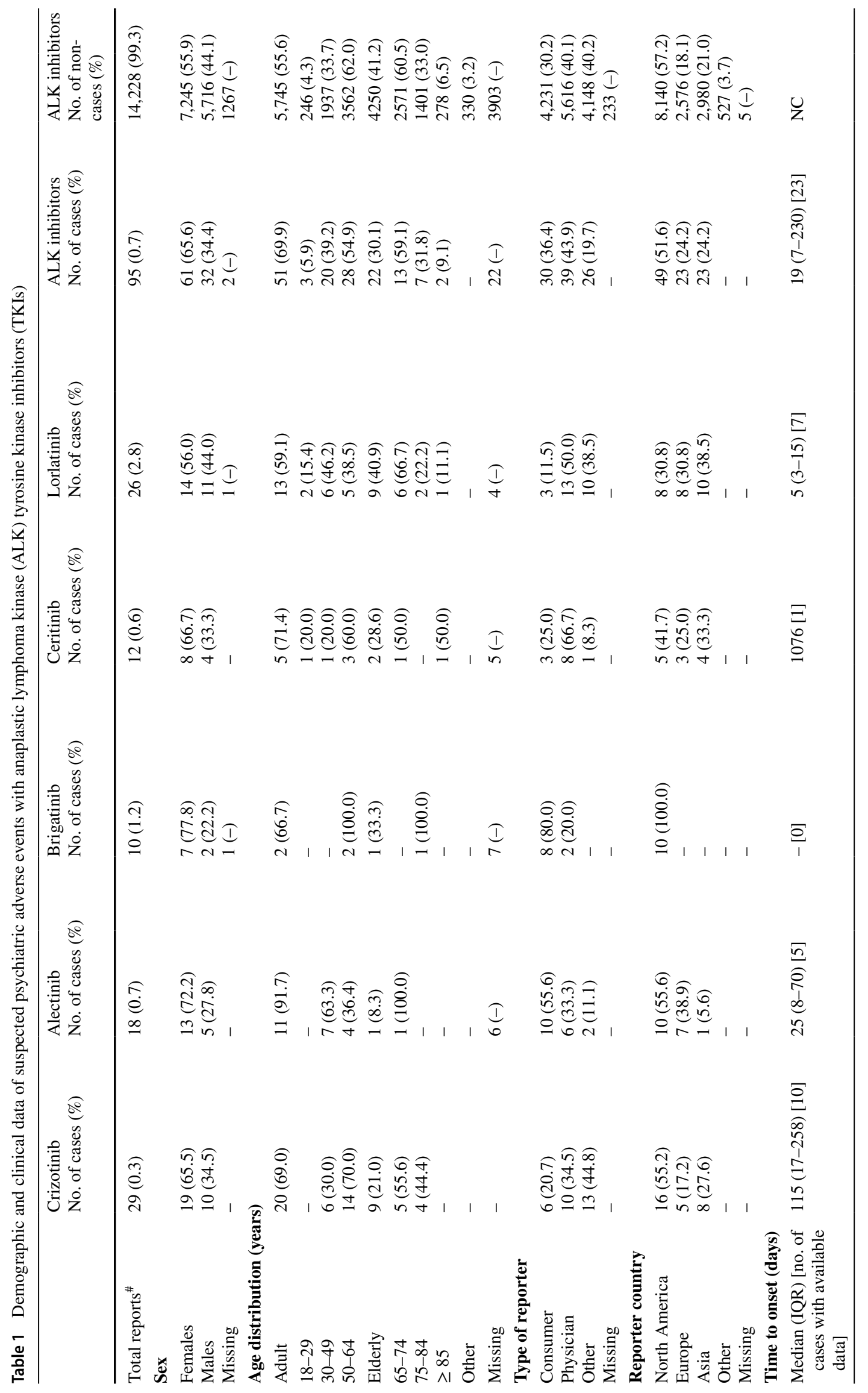




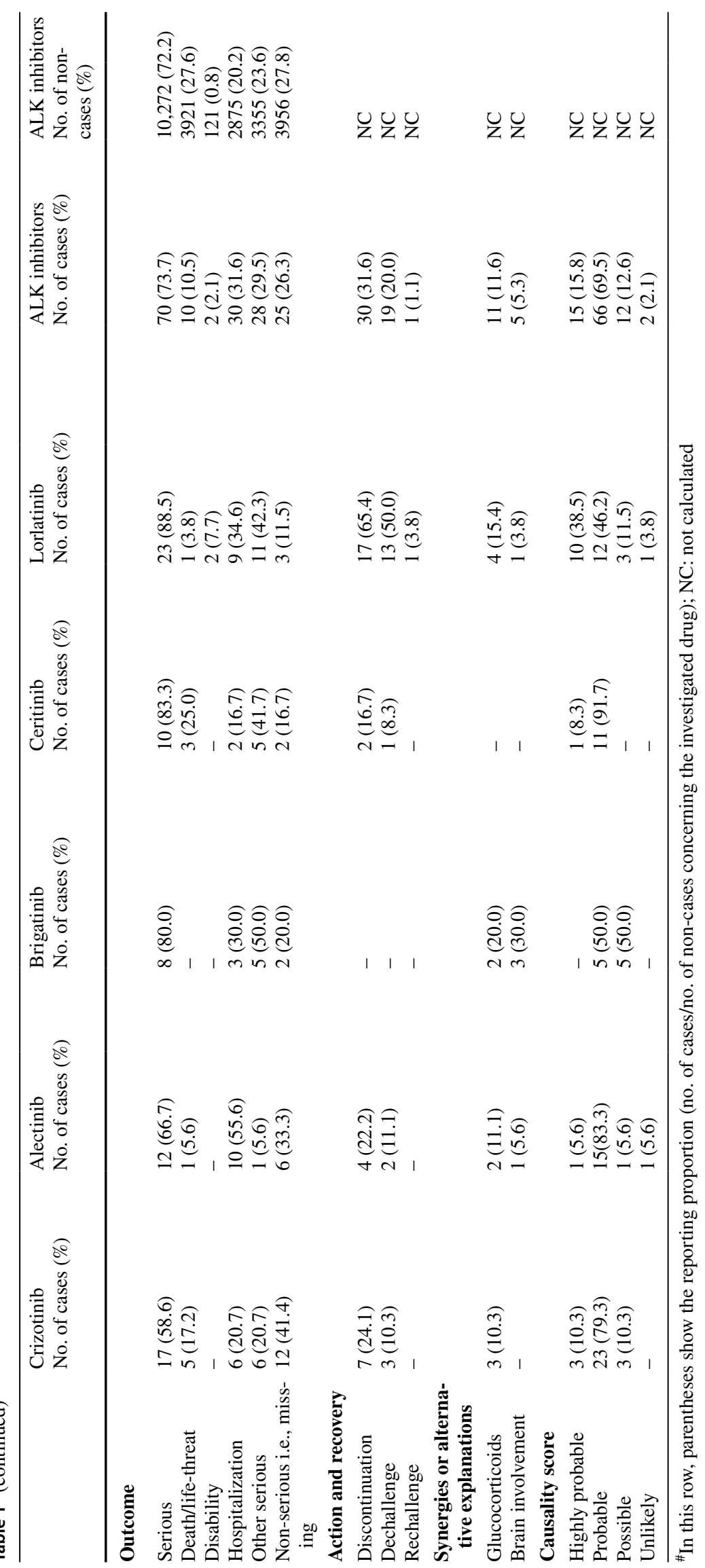


in $31.6 \%$ and $20 \%$ of cases, respectively, with the highest proportion for lorlatinib (65.4\% and 50\%).

According to the adapted probabilistic algorithm for causality assessment, $15.8 \%$ of retained cases were considered as highly probable, $69.5 \%$ as probable, and just $2.1 \%$ as unlikely (ESM).

\section{Discussion}

In recent years, the development of ALK inhibitors has improved the survival outcomes of advanced ALK-rearranged NSCLC patients. In addition, the AEs with ALK TKIs are fairly well known, although emerging data are starting to accrue from pharmacovigilance [17]. Spontaneous reporting systems are needed to identify and better characterize the different AEs in a timely manner in the real world, thus increasing awareness by oncologists to handle them promptly.

In our opinion, reported psychiatric disorders represent AEs of special interest as they often are underestimated and could have an unfavorable impact on patients' personal and social functioning.

The mechanism underlying psychiatric AEs to ALK inhibitors is unclear, although ALK can play a role in the internalization and regulation of dopamine $\mathrm{D} 2$ receptor (D2R), a G protein-coupled receptor expressed in brain regions that control motor function, cognition, and motivation. Its dysregulation may be involved in psychiatric disorders. Its agonist-mediated activation initially inhibits the firing of dopaminergic neurons, while prolonged exposure to dopamine desensitizes D2Rs. In mice models, ALK inhibition was demonstrated to block the recovery of inhibition by dopamine in ventral tegmental area slices [18]. Using a cell-based system, it was demonstrated that ALK is involved in D2R desensitization by promoting endocytosis in response to prolonged dopamine stimulation through a double mechanism of transactivation with $\mathrm{D} 2 \mathrm{R}$ and of signaling mediated by protein kinase $\mathrm{C}$ (Fig. 2) [19].

To the best of our knowledge, our work is the first realworld pharmacovigilance study on psychiatric AEs to

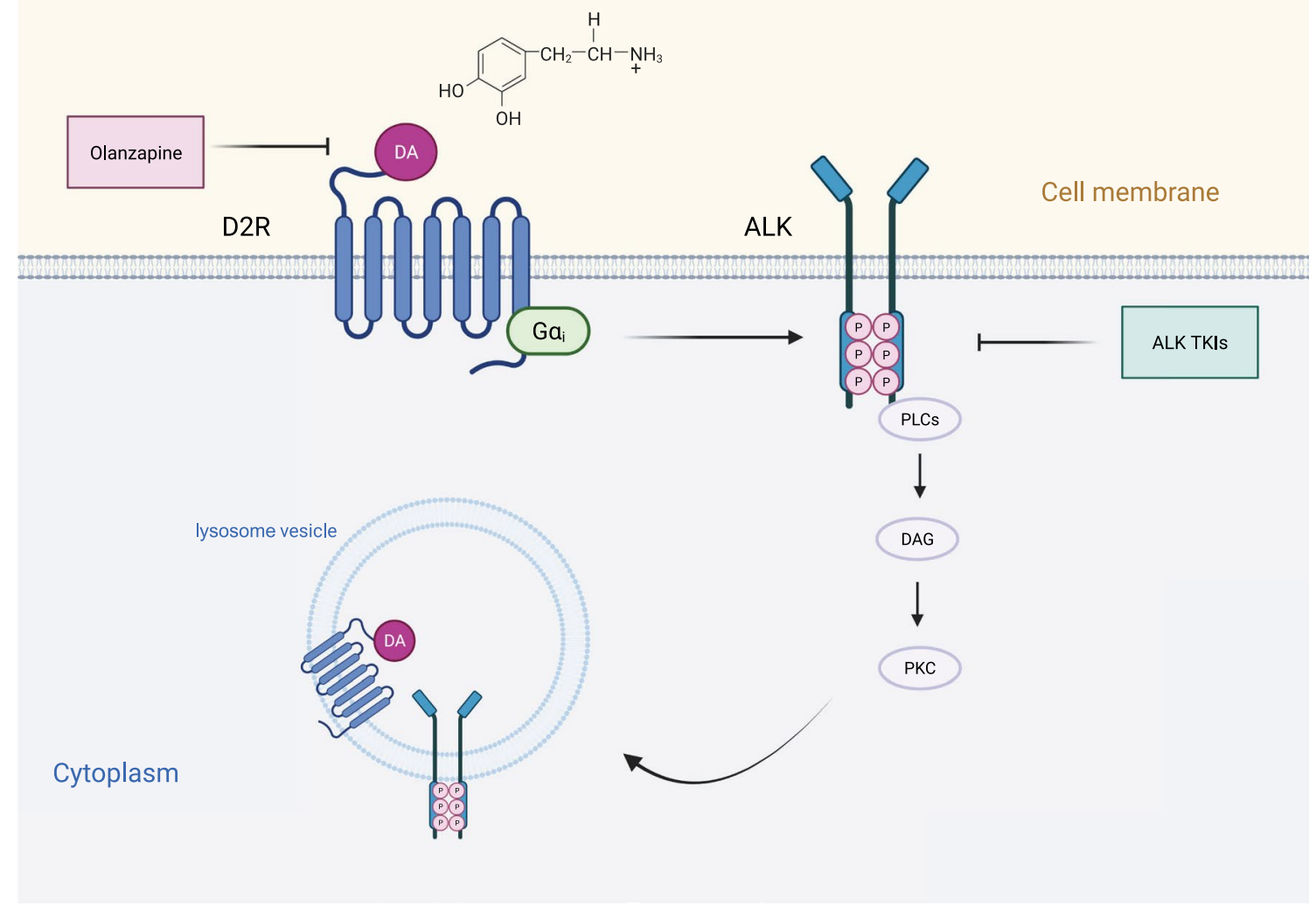

Fig. 2 Potential mechanism of ALK involvement in D2R internalization. Prolonged exposure to dopamine (DA) desensitizes dopamine D2 receptor (D2R) promoting recovery of firing dopaminergic neurons. D2R desensitization mechanism involves anaplastic lymphoma kinase (ALK) through its transactivation and association with D2R; in particular, phosphorylated ALK binds to phospholipase C (PLC) and promotes, in a downstream pathway mediated by protein kinase $\mathrm{C}$ (PKC), internalization of the D2R and subsequent lysosomal degradation. Blocking activation of ALK inhibits endocytosis of D2R and recovery of firing dopaminergic neurons. Olanzapine is an atypical antipsychotic agent, and its activity is achieved by the antagonism of multiple neuronal receptors, including D2R. DAG diacylglycerol 
ALK inhibitors in NSCLC patients. While most of the preapproval data concerned lorlatinib, we also found a nonnegligible number of events with other ALK inhibitors, including first- and second-generation agents, thus raising the hypothesis of a class effect.

The highest reporting frequency of psychiatric AEs with lorlatinib also found in our study could be explained by this agent's remarkable ability to penetrate the blood-brain barrier (BBB) and its low propensity for P-glycoprotein (P-gp) efflux [20]. The macrocyclic structural characteristics that confer these properties to lorlatinib could explain its higher accumulation in the CNS being responsible for psychiatric AEs [21, 22]. However, lorlatinib could act as a trigger after a prolonged D2R desensitization exerted by a first- and/or second-generation ALK TKI, although this remains a speculative explanation due to the lack of data regarding the use of lorlatinib (first-line versus subsequent lines) in the current FAERS analysis.

On the other hand, the non-negligible proportion of psychiatric events with crizotinib deserves further discussion. Collectively, pharmacokinetic data could suggest the low BBB penetrance of crizotinib results in worst CNS activity, as compared to alectinib and lorlatinib [23]. However, patient-related factors, especially CNS radiation, but also severe renal impairment as well as drug-drug interactions, can increase BBB penetrance [24-26] and possibly explain the observed neurocognitive toxicity. Of note, the reported onset of psychiatric AEs with crizotinib in the present study was delayed and the proportion of subjects requiring discontinuation was lower as compared to lorlatinib.

We acknowledge the limitations of our work. In particular, the retrospective nature of the study and the lack of exposure and clinical data (including missing data, comorbidities, and radiation therapy), which do not allow to infer firm causality and calculate real incidence. Moreover, FAERS is a self-reported database used for identifying potential relationship between drugs and AEs in post-marketing surveillance of drug safety, and submission to this platform is not mandatory for physicians.

There are no reasons to support the existence of confounding by indication or channeling bias (i.e., preferential prescription towards more severe patients), although other reporting biases cannot be ruled out with certainty due to different approval times and market penetration of the various ALK TKIs. We also apply stringent exclusion criteria, which, together with the likely under-reporting, may potentially underestimate actual psychiatric events.

Nonetheless, several strengths can be identified. We used a large-scale publicly accessible pharmacovigilance database, thus supporting generalizability of the results, and contributed to the cumulative knowledge about the safety of ALK inhibitors in an unselected real-world population, a topic still poorly investigated.
Current evidence suggest that, with the appearance of psychiatric disorders, antipsychotic therapy must be started. Olanzapine is one of the preferred antipsychotic drugs because it can be safely administered with concomitant ALK TKIs. Co-adjuvant drugs, such as antidepressants and benzodiazepines, can be used; conversely, other antipsychotic drugs, including risperidone and quetiapine, should be used with caution due to drug-drug interactions [27].

\section{Conclusions}

Taken together, our findings raise the hypothesis that psychiatric AEs, though rare, represent a safety issue with all ALK TKIs, and support psychiatric disorders as actual adverse drug reactions to ALK TKIs; oncologists should be aware of the onset of depression, anxiety, and mood alterations and patients and caregivers should be advised about psychiatric toxicities. Moreover, a mental state examination should be performed before beginning ALK TKI therapy and a specialist consultation may be required for patients who develop psychiatric symptoms before evaluating dose reduction or discontinuation therapy. Large prospective populationbased studies are warranted to establish actual event rates and fully elucidate risk factors that might lead to proper risk management.

Supplementary Information The online version contains supplementary material available at https://doi.org/10.1007/s11523-021-00865-8.

\section{Declarations}

Funding This research did not receive any specific grant from funding agencies in the public, commercial, or not-for-profit sectors. Authors from the University of Bologna (Emanuel Raschi, Andrea Ardizzoni) are supported by Institutional Research Funds (Ricerca Fondamentale Orientata).

Conflicts of interest/Competing interests Dr. F. Facchinetti reports personal fees from BMS and ROCHE, outside the submitted work. Prof. A. Ardizzoni reports grants and personal fees from BMS, personal fees from Eli-Lilly, Pfizer, MSD and Boehringer; grants from Celgene, outside the submitted work. Dr. F. Gelsomino reports personal fees from AstraZeneca and Eli-Lilly, outside the submitted work. Prof E. Raschi reports personal fees from Novartis, outside the submitted work. Dr. M. Sisi, Dr. M. Fusaroli, Dr. A. De Giglio declare that they have no conflicts of interest that might be relevant to the contents of this article.

Ethics approval Not applicable.

Consent to participate Not applicable.

Consent for publication Not applicable.

Availability of data and material and code availability The datasets generated and/or analyzed during the current study are available in the Food and Drug Administration Adverse Events Reporting System 
(FAERS) repository, [https://fis.fda.gov/sense/app/d10be6bb-494e4cd2-82e4-0135608ddc13/sheet/7a47a261-d58b-4203-a8aa-6d302 $1737452 /$ state/analysis].

Author contributions Conceptualization: Emanuel Raschi, Francesco Gelsomino. Data curation: Monia Sisi, Michele Fusaroli, Andrea De Giglio, Emanuel Raschi, Francesco Gelsomino. Investigation: Monia Sisi, Michele Fusaroli, Andrea De Giglio, Emanuel Raschi, Francesco Gelsomino. Visualization: Monia Sisi, Michele Fusaroli, Andrea De Giglio, Francesco Facchinetti, Andrea Ardizzoni, Emanuel Raschi, Francesco Gelsomino. Writing-original draft preparation: Monia Sisi. Writing-reviewing and editing: Michele Fusaroli, Andrea De Giglio, Francesco Facchinetti, Andrea Ardizzoni, Emanuel Raschi, Francesco Gelsomino. Supervision: Andrea Ardizzoni, Emanuel Raschi, Francesco Gelsomino. Methodology: Michele Fusaroli, Emanuel Raschi. Software: Michele Fusaroli, Emanuel Raschi. All authors read and approved the final version of the paper.

Open Access This article is licensed under a Creative Commons Attribution-NonCommercial 4.0 International License, which permits any non-commercial use, sharing, adaptation, distribution and reproduction in any medium or format, as long as you give appropriate credit to the original author(s) and the source, provide a link to the Creative Commons licence, and indicate if changes were made. The images or other third party material in this article are included in the article's Creative Commons licence, unless indicated otherwise in a credit line to the material. If material is not included in the article's Creative Commons licence and your intended use is not permitted by statutory regulation or exceeds the permitted use, you will need to obtain permission directly from the copyright holder. To view a copy of this licence, visit http://creativecommons.org/licenses/by-nc/4.0/.

\section{References}

1. Pikor LA, Ramnarine VR, Lam S, Lam WL. Genetic alterations defining NSCLC subtypes and their therapeutic implications. Lung Cancer. 2013;82(2):179-89. https://doi.org/10.1016/j.lungc an.2013.07.025

2. Shaw AT, Yeap BY, Mino-Kenudson M, Digumarthy SR, Costa DB, Heist RS, et al. Clinical features and outcome of patients with non-small-cell lung cancer who harbor EML4-ALK. J Clin Oncol. 2009;27(26):4247-53. https://doi.org/10.1200/JCO.2009.22.6993.

3. Weickhardt AJ, Aisner DL, Franklin WA, Varella-Garcia M, Doebele RC, Camidge DR. Diagnostic assays for identification of anaplastic lymphoma kinase-positive non-small cell lung cancer. Cancer. 2013;119(8):1467-77. https://doi.org/10.1002/cncr. 27913.

4. Solomon BJ, Mok T, Kim DW, Wu YL, Nakagawa K, Mekhail $\mathrm{T}$, et al; PROFILE 1014 Investigators. First-line crizotinib versus chemotherapy in ALK-positive lung cancer. N Engl J Med. 2014;371(23):2167-77. https://doi.org/10.1056/NEJMoa1408440 (erratum in: N Engl J Med. 2015;373(16):1582).

5. Peters S, Camidge DR, Shaw AT, Gadgeel S, Ahn JS, Kim DW, et al; ALEX Trial Investigators. Alectinib versus crizotinib in untreated ALK-positive non-small-cell lung cancer. N Engl J Med. 2017;377(9):829-838. https://doi.org/10.1056/NEJMoa1704795.

6. Camidge DR, Kim HR, Ahn MJ, Yang JC, Han JY, Lee JS, et al. Brigatinib versus crizotinib in ALK-positive non-small-cell lung cancer. N Engl J Med. 2018;379(21):2027-39. https://doi.org/10. 1056/NEJMoa1810171.

7. Shaw AT, Bauer TM, de Marinis F, Felip E, Goto Y, Liu G, et al; CROWN Trial Investigators. First-line lorlatinib or crizotinib in advanced $A L K$-positive lung cancer. $\mathrm{N}$ Engl $\mathrm{J}$ Med.
2020;383(21):2018-2029. https://doi.org/10.1056/NEJMoa2027 187.

8. Bauer TM, Shaw AT, Johnson ML, Navarro A, Gainor JF, Thurm $\mathrm{H}$, et al. Brain penetration of lorlatinib: cumulative incidences of CNS and non-CNS progression with lorlatinib in patients with previously treated ALK-positive non-small-cell lung cancer. Target Oncol. 2020;15(1):55-65. https://doi.org/10.1007/ s11523-020-00702-4.

9. Mok T, Camidge DR, Gadgeel SM, Rosell R, Dziadziuszko R, Kim DW, et al. Updated overall survival and final progressionfree survival data for patients with treatment-naive advanced ALK-positive non-small-cell lung cancer in the ALEX study. Ann Oncol. 2020;31(8):1056-64. https://doi.org/10.1016/j.annonc. 2020.04.478.

10. Camidge DR, Kim HR, Ahn MJ, Yang JCH, Han JY, Hochmair MJ, et al. Brigatinib versus crizotinib in advanced ALK inhibitor-naive ALK-positive non-small cell lung cancer: second interim analysis of the phase III ALTA-1L trial. J Clin Oncol. 2020;38(31):3592-603. https://doi.org/10.1200/JCO.20.00505.

11. Soria JC, Tan DSW, Chiari R, Wu YL, Paz-Ares L, Wolf J, et al. First-line ceritinib versus platinum-based chemotherapy in advanced ALK-rearranged non-small-cell lung cancer (ASCEND-4): a randomised, open-label, phase 3 study. Lancet. 2017;389(10072):917-929. https://doi.org/10.1016/S01406736(17)30123-X.

12. Rocco D, Battiloro C, Della Gravara L, Gridelli C. Safety and tolerability of anaplastic lymphoma kinase inhibitors in non-smallcell lung cancer. Drug Saf. 2019;42(2):199-209. https://doi.org/ 10.1007/s40264-018-0771-y.

13. Kassem L, Shohdy KS, Lasheen S, Abdel-Rahman O, Ali A, Abdel-Malek RR. Safety issues with the ALK inhibitors in the treatment of NSCLC: a systematic review. Crit Rev Oncol Hematol. 2019;134:56-64. https://doi.org/10.1016/j.critrevonc.2018.11. 004.

14. Bauer TM, Felip E, Solomon BJ, Thurm H, Peltz G, Chioda MD, et al. Clinical management of adverse events associated with lorlatinib. Oncologist. 2019;24(8):1103-10. https://doi.org/10.1634/ theoncologist.2018-0380.

15. Raschi E, Fusaroli M, Ardizzoni A, Poluzzi E, De Ponti F. Thromboembolic events with cyclin-dependent kinase 4/6 inhibitors in the FDA adverse event reporting system. Cancers (Basel). 2021;13(8):1758. https://doi.org/10.3390/cancers13081758.

16. Raschi E, Gatti M, Gelsomino F, Ardizzoni A, Poluzzi E, De Ponti F. Lessons to be learnt from real-world studies on immune-related adverse events with checkpoint inhibitors: a clinical perspective from pharmacovigilance. Target Oncol. 2020;15(4):449-66. https://doi.org/10.1007/s11523-020-00738-6.

17. Omar NE, Fahmy Soliman AI, Eshra M, Saeed T, Hamad A, Abou-Ali A. Postmarketing safety of anaplastic lymphoma kinase (ALK) inhibitors: an analysis of the FDA adverse event reporting system (FAERS). ESMO Open. 2021;6(6): 100315. https://doi. org/10.1016/j.esmoop.2021.100315.

18. Dutton JW 3rd, Chen H, You C, Brodie MS, Lasek AW. Anaplastic lymphoma kinase regulates binge-like drinking and dopamine receptor sensitivity in the ventral tegmental area. Addict Biol. 2017;22(3):665-78. https://doi.org/10.1111/adb.12358.

19. He D, Lasek AW. Anaplastic lymphoma kinase regulates internalization of the dopamine D2 receptor. Mol Pharmacol. 2020;97(2):123-31. https://doi.org/10.1124/mol.119.117473.

20. Shaw AT, Felip E, Bauer TM, Besse B, Navarro A, Postel-Vinay S, et al. Lorlatinib in non-small-cell lung cancer with ALK or ROS1 rearrangement: an international, multicentre, open-label, singlearm first-in-man phase 1 trial. Lancet Oncol. 2017;18(12):1590-9. https://doi.org/10.1016/S1470-2045(17)30680-0.

21. Johnson TW, Richardson PF, Bailey S, Brooun A, Burke BJ, Collins MR, et al. Discovery of (10R)-7-amino-12-fluoro-2,10,16- 
trimethyl-15-oxo-10,15,16,17-tetrahydro-2H-8,4-(metheno) pyrazolo[4,3-h][2,5,11]-benzoxadiazacyclotetradecine-3-carbonitrile (PF-06463922), a macrocyclic inhibitor of anaplastic lymphoma kinase (ALK) and c-ros oncogene 1 (ROS1) with preclinical brain exposure and broad-spectrum potency against ALKresistant mutations. J Med Chem. 2014;57(11):4720-44. https:// doi.org/10.1021/jm500261q.

22. Huang Q, Johnson TW, Bailey S, Brooun A, Bunker KD, Burke $\mathrm{BJ}$, et al. Design of potent and selective inhibitors to overcome clinical anaplastic lymphoma kinase mutations resistant to crizotinib. J Med Chem. 2014;57(4):1170-87. https://doi.org/10.1021/ jm401805h.

23. Hirota T, Muraki S, Ieiri I. Clinical pharmacokinetics of anaplastic lymphoma kinase inhibitors in non-small-cell lung cancer. Clin Pharmacokinet. 2019;58(4):403-20. https://doi.org/10.1007/ s40262-018-0689-7.

24. Costa DB, Kobayashi S, Pandya SS, Yeo WL, Shen Z, Tan W, et al. CSF concentration of the anaplastic lymphoma kinase inhibitor crizotinib. J Clin Oncol. 2011;29(15):e443-5. https:// doi.org/10.1200/JCO.2010.34.1313.

25. Toyokawa G, Seto T, Takenoyama M, Ichinose Y. Insights into brain metastasis in patients with ALK+ lung cancer: is the brain truly a sanctuary? Cancer Metastasis Rev. 2015;34(4):797-805. https://doi.org/10.1007/s10555-015-9592-y.

26. Metro G, Lunardi G, Floridi P, Pascali JP, Marcomigni L, Chiari $\mathrm{R}$, et al. CSF Concentration of crizotinib in two ALK-positive non-small-cell lung cancer patients with cns metastases deriving clinical benefit from treatment. J Thorac Oncol. 2015;10(5):e267. https://doi.org/10.1097/JTO.0000000000000468.

27. Barata F, Aguiar C, Marques TR, Marques JB, Hespanhol V. Monitoring and managing lorlatinib adverse events in the Portuguese clinical setting: a position paper. Drug Saf. 2021;44(8):825-34. https://doi.org/10.1007/s40264-021-01083-x.

\section{Authors and Affiliations}

\section{Monia Sisi ${ }^{1}\left(\right.$ Michele Fusaroli $^{2} \cdot$ Andrea De Giglio $^{1,3} \cdot$ Francesco Facchinetti $^{4} \cdot$ Andrea Ardizzoni $^{1,3} \cdot$ Emanuel Raschi ${ }^{2} \cdot$ Francesco Gelsomino ${ }^{1,3}$}

1 Department of Experimental, Diagnostic and Specialty Medicine, Policlinico S. Orsola-Malpighi, Alma Mater Studiorum-University of Bologna, Bologna, Italy

2 Pharmacology Unit, Department of Medical and Surgical Sciences, Alma Mater Studiorum-University of Bologna, Bologna, Italy
3 Divisione di Oncologia Medica, IRCCS Azienda Ospedaliero-Universitaria di Bologna, Bologna, Italy

4 Institut Gustave Roussy, Inserm, Biomarqueurs Prédictifs et Nouvelles Stratégies Thérapeutiques en Oncologie, Université Paris-Saclay, Villejuif, France 